\title{
Long-term outcomes of total arch replacement using a 4-branched graft
}

Yuki Ikeno, MD, Koki Yokawa, MD, Takashi Matsueda, MD, Katsuhiro Yamanaka, MD, PhD,

Takeshi Inoue, MD, Hiroshi Tanaka, MD, PhD, and Yutaka Okita, MD, PhD

\section{ABSTRACT}

Objective: Our study evaluated the long-term outcomes of total arch replacement using a 4-branched graft.

Methods: From October 1999 to December 2016, 655 patients underwent total arch replacement using a 4-branched graft (pathology in the 655 patients was distributed as 399 no dissection, 149 acute dissection, and 107 chronic dissection). Two hundred nine patients $(31.9 \%)$ underwent nonelective surgery. Mean followup term was $5.0 \pm 4.1$ years and follow-up rate was $97.1 \%$.

Results: Of 655 patients who underwent total arch replacement using a 4-branched graft, operative mortality occurred in 34 patients $(5.2 \%)$ and permanent neurologic deficit occurred in 24 patients $(3.7 \%)$. One hundred ninety late deaths occurred, with 20 aortic event-related deaths. Overall survival was $73.1 \% \pm 1.9 \%$ at 5 years and $54.8 \% \pm 2.7 \%$ at 10 years. Multivariate Cox-hazard regression analysis demonstrated that older age, lower estimated glomerular filtration rate, concurrent procedures, permanent neurologic deficit, tracheostomy, and renal failure were significant risk factors for late death. Freedom from repeat operation on the aorta was $98.0 \% \pm 0.7 \%$ at 5 years and $93.9 \% \pm 1.8 \%$ at 10 years and freedom from additional aortic operation was $87.2 \% \pm 1.5 \%$ at 5 years and $77.3 \% \pm 2.7 \%$ at 10 years. The incidence of pseudoaneursym was $2.2 \%$.

Conclusions: The long-term outcomes for patients undergoing total arch replacement using 4-branched graft are favorable. However, even in the late phase, periodic follow-up is necessary to address subsequent aorta-related events. (J Thorac Cardiovasc Surg 2019;157:75-85)

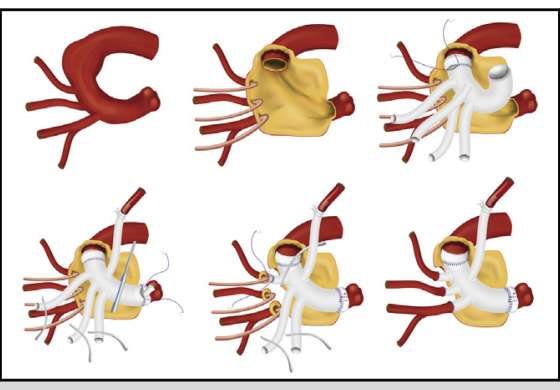

Surgical schema of total arch replacement using a 4-branched graft.

\section{Central Message}

Total arch replacement using 4-branched graft was a desirable procedure from the long-term perspective. Postoperative complications were significant risk factors for late survival.

\section{Perspective}

To improve long-term outcomes following total arch replacement using a 4-branched graft, we have to pay attention to not only postoperative complications but also to late aortic events. Even in the late phase, periodic follow-up is required to prepare for subsequent aortic events.

See Editorial Commentary page 86.
Surgical outcomes for patients undergoing total arch replacement has improved dramatically over the past 2 decades. $^{1-4}$ This achievement has been attributed the development of water-sealed grafts, the evolution of cardiopulmonary bypass technique and equipment, a better understanding of brain protection, and refinement of the surgical procedures. ${ }^{5,6}$ The development of a 4-branched

From the Division of Cardiovascular Surgery, Department of Surgery, Kobe University, Kobe, Japan.

Read at The American Association for Thoracic Surgery Aortic Symposium 2018, New York, New York, April 26-27, 2018.

Received for publication April 26, 2018; revisions received Sept 1, 2018; accepted for publication Sept 4, 2018.

Address for reprints: Yutaka Okita, MD, PhD, Division of Cardiovascular Surgery, Department of Surgery, Kobe University Graduate School of Medicine, 7-5-2 Kusunoki-cho Chuo-ku, Kobe 650-0017, Japan (E-mail: yutakaokita@gmail.com). $0022-5223 / \$ 36.00$

Copyright (c) 2018 by The American Association for Thoracic Surgery

https://doi.org/10.1016/j.jtcvs.2018.09.118 graft has brought the discussion toward total arch replacements. It has several advantages over the island aortic cuff technique when used to reconstruct arch vessels, and it has been widely used. ${ }^{7,8}$ Hospital mortality after elective total arch replacement was $5.7 \%$ in the Japanese Adult Cardiovascular Surgery Database between 2008 and 2013, ${ }^{9}$ and hospital mortality after emergent total arch replacement for acute type A aortic dissection (AADA)

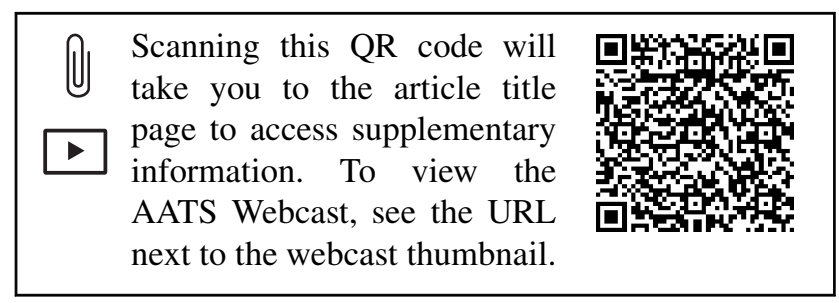




\section{Abbreviations and Acronyms \\ AADA $=$ acute type $\mathrm{A}$ aortic dissection \\ $\mathrm{ACP}=$ antegrade selective cerebral perfusion \\ $\mathrm{CT}=$ computed tomography \\ MAAE $=$ major adverse aortic event \\ PND = permanent neurologic deficit \\ TND $=$ transient neurologic deficit}

was reported to be $10.4 \%$ in the Japanese Association for Thoracic Surgery 2012 registry. ${ }^{10}$

Endovascular treatment or hybrid treatment have also shown lower early mortality and are considered attractive alternatives to conventional surgery, especially for high-risk patients. ${ }^{11-13}$ However, late reintervention is a well-known complication of these procedures. ${ }^{14}$ Because the number of patients with aortic arch disease has been increasing steadily in aging societies, ${ }^{10}$ surgeons are confronted with complex decisions to determine the optimal strategy for treatment by anticipating long-term outcomes for each patient on top of considering early outcomes. However, there are limited data regarding late outcomes following arch repair even in the context of conventional total arch replacement.

The aim of this study was to evaluate the long-term outcomes of patients undergoing total arch replacement using a 4-branched graft.

\section{PATIENTS AND METHODS \\ Study Population}

From October 1999 to December 2016, 661 patients underwent total arch replacement at our institution. Six patients in whom a 4-branched graft was not used for their arch vessels reconstruction were excluded. Six hundred fifty-five patients were eventually included in this study.

Follow-up data were obtained by clinical visit, telephone, or written correspondence and a common closing date (March 2018) was used. Follow-up data were available for all but 19 patients $(2.9 \%)$ who were lost within 1 year of their operation. The mean follow-up period was $5.0 \pm 4.1$ years (range, 0.01-17.9 years). This study protocol was reviewed and approved by our institutional review board. An informed consent waiver was granted due to the design of the study.

\section{Definitions of Clinical Outcomes}

Operative mortality was defined as all 30-day mortality and in-hospital mortality, including any deaths occurring after transfer to another hospital or long-term acute-care facility. ${ }^{15}$ Permanent neurologic deficits (PNDs) were defined as the presence of deficits that persisted at hospital discharge. Transient neurologic deficits (TNDs) were defined as delayed awaking, transient loss of orientation, slurred language, agitation, poor response to comments, and transient hemiparesis that had recovered by hospital discharge.

Acute dissection was defined as $<2$ weeks after symptom onset, whereas chronic dissection was defined as $>2$ weeks after symptom onset. Aortarelated death was defined as death due to aneurysm rupture, aortic dissection, graft infection, and aortic surgery. Repeated aortic operation was defined as surgery on the aorta for graft infection and pseudoaneurysm.
Additional aortic operation was defined as surgery on the aorta for the repair of dilatation of the thoracic and thoracoabdominal aorta. The surgical indication for additional aortic operation was diameter $>50 \mathrm{~mm}$. A major adverse aortic event (MAAE) was defined as aorta-related death; aneurysm rupture; aortic dissection; graft infection; and any subsequent surgery on the aorta, including the entire aorta from aortic root to aortic bifurcation.

The diagnosis of pseudoaneurysm was based on enhanced computed tomography (CT) and CT follow-up was repeated annually as possible. Postoperative CT assessment was performed in 625 patients $(95.4 \%)$ $3.6 \pm 3.7$ years after surgery.

\section{Surgical Approach}

All 655 patients underwent total arch replacement through median sternotomy, and our surgical strategies evolved over time, as described in our previous series (Video 1). ${ }^{4,7}$ Briefly, since 2002, we have exclusively used antegrade selective cerebral perfusion (ACP) for brain protection, with minimal tympanic temperatures between $20^{\circ} \mathrm{C}$ and $23^{\circ} \mathrm{C}$ and minimal rectal temperatures below $30^{\circ} \mathrm{C}$. To prevent left recurrent nerve injury, we made a direct circumferential transection from the inner side of the distal end of the aneurysm without longitudinal incision of the aortic arch. We indicated elephant trunk insertion in patients with DeBakey type I acute aortic dissection, and dilated descending or thoracoabdominal aorta because patients did not have atherothrombotic plaque in the descending aorta. After the distal anastomosis, antegrade perfusion of the lower body and rewarming was started. Subsequently, the proximal anastomosis was performed, followed by coronary reperfusion. Finally, the aortic arch was divided to make arch vessel buttons. Three arch vessels were reconstructed individually using a 4-branched graft and 5-0 polypropylene sutures. However, in 13 patients with severe carotid artery stenosis and atherothrombotic plaque, arch vessel reconstruction was prioritized to proximal anastomosis to decrease ACP time.

\section{Statistical Analysis}

All continuous variables were expressed as mean \pm standard deviation or median (interquartile range [25th-75th percentile]). Categorical

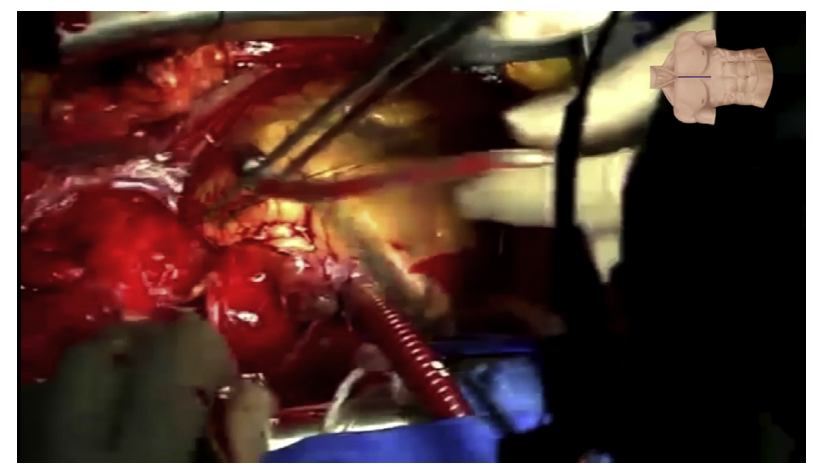

VIDEO 1. The aortic arch was opened under moderate hypothermic circulatory arrest with antegrade selective cerebral perfusion for brain protection. To prevent left recurrent nerve injury, we made a direct circumferential transection from the inner side of the distal end of the aneurysm without longitudinal incision of the aortic arch. After the distal anastomosis, antegrade perfusion of the lower body and rewarming was started. Subsequently, the proximal anastomosis was performed, followed by coronary reperfusion. Finally, the aortic arch was divided to make arch vessel buttons. Three-arch vessels were reconstructed, individually, using a 4-branched graft and 5-0 polypropylene sutures. Video available at: https:// www.jtcvs.org/article/S0022-5223(18)32823-X/fulltext. 
TABLE 1. Patient characteristics

\begin{tabular}{|c|c|c|c|c|c|}
\hline Variable & Overall $(n=655)$ & $\begin{array}{l}\text { No dissection } \\
\quad(\mathbf{n}=399)\end{array}$ & $\begin{array}{l}\text { Acute dissection } \\
\quad(n=149)\end{array}$ & $\begin{array}{l}\text { Chronic dissection } \\
\quad(\mathbf{n}=107)\end{array}$ & $P$ value \\
\hline Age (y) & $70.1 \pm 11.9$ & $74.3 \pm 8.5$ & $61.5 \pm 13.1$ & $66.4 \pm 13.6$ & $<.001^{*}$ \\
\hline Octogenarian & $127(19.3)$ & $102(25.6)$ & $11(7.4)$ & $14(13.1)$ & $<.001^{*}$ \\
\hline Female & $190(29.0)$ & $91(22.8)$ & $54(36.2)$ & $45(42.1)$ & $<.001 *$ \\
\hline Hypertension & $521(79.5)$ & $333(83.5)$ & $103(69.1)$ & $85(79.4)$ & $.002^{*}$ \\
\hline Dyslipidemia & $189(28.9)$ & $144(36.1)$ & $18(12.1)$ & $27(25.2)$ & $<.001^{*}$ \\
\hline Diabetes mellitus & $83(12.7)$ & $71(17.8)$ & $7(4.7)$ & $5(4.7)$ & $<.001 *$ \\
\hline Smoking & $399(60.9)$ & $294(73.7)$ & $59(39.6)$ & $46(43.0)$ & $<.001 *$ \\
\hline eGFR $\left(\mathrm{mL} / \mathrm{min} / 1.73 \mathrm{~m}^{2}\right)$ & $57.3 \pm 22.3$ & $55.0 \pm 21.2$ & $62.0 \pm 24.1$ & $59.0 \pm 22.6$ & $.003^{*}$ \\
\hline Chronic lung disease & $134(20.4)$ & $114(28.6)$ & $2(1.3)$ & $18(16.8)$ & $<.001 *$ \\
\hline Coronary artery disease & $174(26.6)$ & $142(35.6)$ & $10(6.7)$ & $22(20.6)$ & $<.001^{*}$ \\
\hline Marfan syndrome & $16(2.4)$ & $0(0)$ & $7(4.7)$ & $9(8.4)$ & $<.001^{*}$ \\
\hline Old cerebral infarction & 77 (11.8) & $50(12.5)$ & $13(8.7)$ & $14(13.1)$ & .400 \\
\hline Previous thoracic aortic surgery & $72(11.0)$ & $24(6.0)$ & $7(4.7)$ & $41(38.3)$ & $<.001 *$ \\
\hline Atherothrombotic aorta & $46(7.0)$ & $40(10.0)$ & $1(0.7)$ & $5(4.7)$ & $<.001 *$ \\
\hline Malperfusion & $46(7.0)$ & $0(0)$ & $46(30.9)$ & $0(0)$ & $<.001 *$ \\
\hline Brain malperfusion & $15(2.3)$ & $0(0)$ & $15(10.1)$ & $0(0)$ & $<.001^{*}$ \\
\hline Shock status & $36(5.5)$ & $12(3.0)$ & $21(14.1)$ & $3(2.8)$ & $<.001^{*}$ \\
\hline Cardiac arrest & $8(1.2)$ & $2(0.5)$ & $6(4.0)$ & $0(0)$ & $.004^{*}$ \\
\hline Intubated & $8(1.2)$ & $4(1.0)$ & $3(2.0)$ & $1(0.9)$ & .634 \\
\hline Infection & $18(2.7)$ & $11(2.8)$ & $0(0)$ & $7(6.5)$ & $.002 *$ \\
\hline Rupture & $40(6.1)$ & $34(8.5)$ & $2(1.3)$ & $4(3.7)$ & $.001 *$ \\
\hline Elective & $446(68.1)$ & $353(88.5)$ & $3(2.0)$ & $90(84.1)$ & $<.001^{*}$ \\
\hline Urgent & $38(5.8)$ & $13(3.3)$ & $15(10.1)$ & $10(9.4)$ & $.003^{*}$ \\
\hline Emergent & $171(26.1)$ & $33(8.3)$ & $131(87.9)$ & $7(6.5)$ & $<.001 *$ \\
\hline
\end{tabular}

Values are presented as mean \pm standard deviation or $\mathrm{n}(\%) . e G F R$, Estimated glomerular filtration rate. ${ }^{*} P<.05$.

variables are expressed as the number and percentage of patients. Data were analyzed by the $\chi^{2}$ test for categoric variables. Assumption of normality of continuous data was tested with the Shapiro-Wilk test. If assumption of normality was met, continuous variables were compared using the Student $t$ test, whereas the Mann-Whitney $U$ test was used for nonparametric variables. The values of overall late survival, freedom from aorta-related death, freedom from repeated surgery on the aorta, freedom from additional surgeries on the aorta, MAAE-free survival, and freedom from stroke were computed using the Kaplan-Meier methods and was expressed as the rate \pm standard error. Death was modeled as a competing risk in freedom from repeated surgery on the aorta, freedom from additional surgeries on the aorta, MAAE-free survival, and freedom from stroke analyses. The comparison of Kaplan-Meier curves was performed using log-rank test. Univariate risk factor analysis of overall survival was performed on the cumulative incidence function using Cox regression and hazard ratio (HR) with $95 \%$ confidence interval (CI). $P<.05$ in the univariate analysis was defined for selecting variables for entry into the multivariate regression analysis for overall survival. Comparison of patient survival with the general age- and sex-matched population was performed using the Japanese population life table available from the Japanese Ministry of Health, Labor, and Welfare, ${ }^{16}$ according to the methods outlined by Finkelstein and colleagues. ${ }^{17}$ All data analyses were performed with JMP software version 11.0 (SAS Institute Inc, Cary, NC).

\section{RESULTS}

\section{Patient Characteristics}

Preoperative patient characteristics are shown in Table 1. Aortic pathologies were classified into 3 groups: no dissection $(\mathrm{n}=399[60.9 \%])$; acute dissection $(\mathrm{n}=149[22.7 \%]$ including AADA in 143); and chronic dissection ( $\mathrm{n}=107$ [16.3\%] including previous AADA repair in 37, type A dissection in 25 , and type $B$ dissection in 45 ). Mean age was $70.1 \pm 11.9$ years (no dissection: $74.3 \pm 8.5$ years, acute dissection: $61.5 \pm 13.1$ years, and chronic dissection: $66.4 \pm 13.6$ years $)(P<.001)$, and 127 patients $(19.4 \%)$ were octogenarians/nonagenarians. Regarding preoperative hemodynamic status, patients with shock status-defined as systolic blood pressure $<90 \mathrm{~mm} \mathrm{Hg}(\mathrm{n}=37$ [5.5\%]), cardiac arrest $(n=8[1.2 \%])$, infection $(n=18[2.7 \%])$, rupture $(n=40[6.1 \%])$, and brain malperfusion $(n=15$ $[2.3 \%])$-were included. Forty-seven patients $(7.2 \%)$ underwent resternotomy. Emergent surgery was performed in 171 patients $(26.1 \%)$, urgent surgery was performed in 
TABLE 2. Operative data

\begin{tabular}{|c|c|c|c|c|c|}
\hline Variable & $\begin{array}{c}\text { Overall } \\
(n=655)\end{array}$ & $\begin{array}{l}\text { No dissection } \\
\quad(\mathbf{n}=\mathbf{3 9 9})\end{array}$ & $\begin{array}{l}\text { Acute dissection } \\
\qquad(\mathrm{n}=149)\end{array}$ & $\begin{array}{l}\text { Chronic dissection } \\
\quad(\mathbf{n}=107)\end{array}$ & $P$ value \\
\hline Operative time (min) & $424.3 \pm 152.7$ & $399.7 \pm 141.6$ & $465.5 \pm 169.8$ & $459.1 \pm 150.3$ & $<.001^{*}$ \\
\hline CPB time (min) & $193.0 \pm 67.6$ & $177.7 \pm 56.6$ & $231.9 \pm 78.9$ & $197.10 \pm 67.3$ & $<.001^{*}$ \\
\hline Myocardial ischemic time (min) & $92.9 \pm 47.1$ & $77.3 \pm 33.6$ & $125.5 \pm 49.9$ & $105.7 \pm 58.2$ & $<.001^{*}$ \\
\hline Circulation arrest of lower body (min) & $44.0 \pm 16.8$ & $40.6 \pm 15.4$ & $53.7 \pm 17.9$ & $42.9 \pm 14.7$ & $<.001^{*}$ \\
\hline Antegrade cerebral perfusion & $606(92.5)$ & $370(92.7)$ & $142(95.3)$ & $94(87.9)$ & .191 \\
\hline Cerebral perfusion time (min) & $100.8 \pm 39.4$ & $92.7 \pm 33.3$ & $126.4 \pm 45.1$ & $95.4 \pm 37.4$ & $<.001 *$ \\
\hline Minimal tympanic temperature $\left({ }^{\circ} \mathrm{C}\right)$ & $21.0 \pm 2.1$ & $21.1 \pm 2.1$ & $20.8 \pm 1.9$ & $20.8 \pm 2.3$ & .319 \\
\hline Minimal rectal temperature $\left({ }^{\circ} \mathrm{C}\right)$ & $25.9 \pm 2.2$ & $26.1 \pm 2.2$ & $25.6 \pm 2.2$ & $25.7 \pm 1.8$ & $.031^{*}$ \\
\hline Concurrent procedures & $235(35.9)$ & $157(39.4)$ & $34(22.8)$ & $44(41.1)$ & $<.001^{*}$ \\
\hline Coronary artery bypass grafting & $150(22.9)$ & $127(31.8)$ & $7(4.7)$ & $16(15.0)$ & $<.001^{*}$ \\
\hline Aortic valve replacement & $21(3.2)$ & $15(3.8)$ & $0(0)$ & $6(5.6)$ & $.003^{*}$ \\
\hline Aortic root replacement & $41(6.3)$ & $8(2.0)$ & $14(9.4)$ & $19(17.8)$ & $<.001^{*}$ \\
\hline Valve-sparing reimplantation & $26(4.0)$ & $3(0.8)$ & $13(8.7)$ & $10(9.4)$ & $<.001^{*}$ \\
\hline Mitral valve surgery & $6(0.9)$ & $4(1.0)$ & $1(0.7)$ & $1(0.9)$ & .932 \\
\hline Elephant trunk insertion & $244(37.2)$ & $50(12.5)$ & $138(92.6)$ & $56(52.3)$ & $<.001 *$ \\
\hline Frozen elephant trunk & $28(4.3)$ & $3(0.8)$ & $22(14.8)$ & $3(2.8)$ & .097 \\
\hline
\end{tabular}

Values are presented as mean \pm standard deviation or $\mathrm{n}(\%)$. $C P B$, Cardiopulmonary bypass. $* P<.05$.

38 patients $(5.8 \%)$, and 466 patients $(68.1 \%)$ underwent elective surgery.

\section{Operative Details}

Operation-related data are shown in Table 2. The mean cardiopulmonary bypass time was $193.0 \pm 67.6$ minutes, mean myocardial ischemia time was $92.9 \pm 47.1$ minutes, mean lower body circulatory arrest time was $44.0 \pm 16.8$ minutes, and mean cerebral perfusion time was $100.8 \pm$ 39.4 minutes. Concurrent procedures were performed in 235 patients $(35.9 \%)$ and 150 of those $(22.9 \%)$ underwent coronary artery bypass grafting. Two hundred forty-three patients underwent elephant trunk insertion (50 patients in the no dissection group, 138 patients in the acute dissection group, and 55 patients in the chronic dissection group).

\section{Early Outcomes}

Early outcomes are shown in Table 3. The overall operative mortality was $5.2 \%$ (34 out of 655 patients). The 30 -day mortality was $2.7 \%$ (18 out of 655 patients). Hospital mortality was $5.2 \%$ (34 out of 655 patients). Operative mortality was $3.1 \%$ in those undergoing elective surgery (14 out of 446 patients) and $9.6 \%$ in those undergoing nonelective surgery (20 out of 209 patients). The cause of

TABLE 3. Early outcomes

\begin{tabular}{|c|c|c|c|c|c|}
\hline Variable & $\begin{array}{c}\text { Overall } \\
(n=655)\end{array}$ & $\begin{array}{l}\text { No dissection } \\
\quad(\mathbf{n}=399)\end{array}$ & $\begin{array}{l}\text { Acute dissection } \\
\quad(n=149)\end{array}$ & $\begin{array}{l}\text { Chronic dissection } \\
\quad(n=107)\end{array}$ & $P$ value \\
\hline Operative mortality & $34(5.2)$ & $18(4.5)$ & $14(9.4)$ & $2(1.9)$ & $.019^{*}$ \\
\hline 30-d mortality & $18(2.7)$ & $7(1.8)$ & $9(6.0)$ & $2(1.9)$ & $.038^{*}$ \\
\hline Hospital mortality & $34(5.2)$ & $18(4.5)$ & $14(9.4)$ & $2(1.9)$ & $.019^{*}$ \\
\hline 1-y mortality & $77(12.1)$ & $49(12.7)$ & $21(14.5)$ & $7(6.6)$ & .111 \\
\hline Permanent neurologic deficit & $24(3.7)$ & $10(2.5)$ & $13(8.7)$ & $1(0.9)$ & $.002 *$ \\
\hline Transient neurologic deficit & $64(9.8)$ & $38(9.5)$ & $19(12.8)$ & $7(6.5)$ & .243 \\
\hline Mediastinitis & $11(1.7)$ & $5(1.3)$ & $5(3.4)$ & $1(0.90)$ & .238 \\
\hline Tracheostomy & $51(7.8)$ & $33(8.3)$ & $12(8.1)$ & $6(5.7)$ & .661 \\
\hline Hoarseness & $96(14.7)$ & $68(17.0)$ & $13(8.7)$ & $15(14.0)$ & $.038^{*}$ \\
\hline Renal failure & $40(6.1)$ & $27(6.8)$ & $12(8.1)$ & $1(1.0)$ & $.014^{*}$ \\
\hline Hospital stay (d) & $24(17-35)$ & $23(17-35)$ & $25(18-39.8)$ & $25(18-33)$ & .244 \\
\hline Discharge to home & $499(80.4)$ & $322(84.5)$ & $96(71.1)$ & $81(77.1)$ & $.003^{*}$ \\
\hline
\end{tabular}

Values are presented as $\mathrm{n}(\%) . * P<.05$. 
TABLE 4. Cause of late death

\begin{tabular}{lc}
\hline \multicolumn{1}{c}{ Variable } & n (\%) \\
\hline Overall & 191 \\
Aortic & $21(11.0)$ \\
$\quad$ Aneurysm rupture & 9 \\
Graft infection & 5 \\
$\quad$ Aortic dissection & 1 \\
$\quad$ Subsequent aortic surgery & 6 \\
Cardiac & $17(8.9)$ \\
Cerebrovascular accident & $20(10.5)$ \\
Pulmonary & $39(20.4)$ \\
Renal & $14(7.3)$ \\
Malignancy & $33(17.3)$ \\
Gastrointestinal & $5(2.6)$ \\
Sepsis & $10(5.2)$ \\
Elderly age & $9(4.7)$ \\
Trauma & $2(1.0)$ \\
Sudden death & $5(2.6)$ \\
Unknown & $16(8.4)$ \\
\hline
\end{tabular}

death was cerebrovascular accident in 11 patients, sepsis in 6 patients, necrosis of the intestine in 5 patients, pulmonary complications in 9 patients, and hemorrhage in 3 patients.

Regarding postoperative complications, PND and TND occurred in 24 patients $(3.7 \%)$ and in 64 patients $(9.8 \%)$, respectively. Mediastinitis occurred in 11 patients $(1.7 \%)$. Tracheostomy was required in 51 patients $(7.8 \%)$. New hoarseness occurred in 96 patients $(14.7 \%)$. Renal failure developed in 40 patients $(6.1 \%)$.

\section{Late Outcomes}

Survival. During the observation period, 191 late deaths occurred, including 21 aorta-related deaths. The causes of late death are summarized in Table 4. Overall survival was $73.1 \% \pm 1.9 \%$ at 5 years and $54.8 \% \pm 2.7 \%$ at 10 years (median survival time, 11.3 years) (Figure 1, $A$ ). Across the study period, overall survival was $65.9 \% \pm 4.2 \%$ during the first 6 years (1999-2004), $76.6 \% \pm 2.9 \%$ during the second 6 years $(2005-2010)$, and $73.6 \% \pm 3.4 \%$ during the last 6 years $(2011-2016)$ $(P=.597)$ (Figure E1). Stratified with aortic pathologies, 5 -year survival was significantly lower in the no dissection group (no dissection, $68.6 \% \pm 2.6 \%$; acute dissection, $81.3 \% \pm 3.4 \%$; and chronic dissection, $78.0 \% \pm 4.4 \%$ ) $(P<.001)$ (Figure 1, B), whereas the differences between the healthy population and overall survival were similar across the 3 groups (Figure 1, C-E).

Univariate Cox-hazard regression analysis revealed that older age, lower estimated glomerular filtration rate, chronic lung disease, coronary artery disease, old cerebral infarction, nondissection aneurysm, preoperative cardiac arrest, ruptured aneurysm, and concurrent procedures were significant risk factors for late death. On the other hand, Marfan syndrome was found to be a significant positive prognostic factor of survival. In addition, PND, tracheostomy, hoarseness, and renal failure were significant risk factors of late death (Table 5).

Multivariate Cox-hazard regression analysis demonstrated that older age (HR, 1.06; 95\% CI, 1.04-1.08; $P<.001)$, lower estimated glomerular filtration rate (HR, 0.98; 95\% CI, 0.97-0.99; $P<.001)$, concurrent procedures (HR, 1.41; 95\% CI, 1.01-2.11; $P=.043$ ), PND (HR, 3.31; 95\% CI, 1.79-5.79; $P<.001$ ), tracheostomy (HR, 2.38; 95\% CI, 1.53-3.60; $P<.001$ ), and renal failure (HR, $2.53,95 \% \mathrm{CI}, 1.57-3.97 ; P<.001)$ were significant risk factors for late death (Table 5).

Freedom from aorta-related death was $91.5 \% \pm 1.2 \%$ at 5 years and $90.3 \% \pm 1.4 \%$ at 10 years (Figure E2, $A$ ). Stratified with aortic pathologies, freedom from aorta-related death at 5 years was similar within groups (no dissection, $91.5 \% \pm 1.6 \%$; acute dissection, $89.9 \% \pm 2.5 \%$; and chronic dissection, $93.6 \% \pm 2.6 \%[P=.289])$ (Figure E2, B).

Reoperation. One hundred two patients required reoperation, including 18 repeated aorta operations $(2.7 \%)$ and 85 additional aorta operations (13.0\%). The details of reoperations performed in our patients is shown in Table 6 . Freedom from repeated aorta operation was $98.0 \% \pm 0.7 \%$ at 5 years and $93.9 \% \pm 1.8 \%$ at 10 years (Figure 2, A). In each pathology group, freedom from repeated aorta operation at 5 years was significantly worse in the acute dissection group (no dissection, $99.4 \% \pm 0.4 \%$; acute dissection, $93.4 \% \pm 2.7 \%$; and chronic dissection, $99.0 \% \pm 1.0 \%)(P=.004)$ (Figure 2, $B)$. Freedom from additional operations on the aorta was $87.4 \% \pm 1.5 \%$ at 5 years and $77.1 \% \pm 2.7 \%$ at 10 years (Figure 2, C). In each pathology group, freedom from additional aortic operation at 5 years was significantly worse in the chronic dissection group (no dissection, $90.2 \% \pm 1.8 \%$; acute dissection, $89.8 \% \pm 3.0 \%$; and chronic dissection, $75.5 \% \pm 4.6 \%)(P<.001)$ (Figure 2, $D)$. Forty-four additional repairs $(53.7 \%)$ were performed due to distal residual dissection and included descending aorta replacement $(n=9)$, thoracoabdominal aortic aneurysm repair $(n=26)$, and thoracic endovascular aortic repair $(n=9)$.

Events. MAAE-free survival was $57.7 \% \pm 2.2 \%$ at 5 years and $36.4 \% \pm 2.6 \%$ at 10 years (Figure E3, A). Stratified with aortic pathologies, MAAE-free survival at 5 years was similar in the 3 groups (no dissection, $55.9 \% \pm 2.5 \%$; acute dissection, $63.9 \% \pm 4.3 \%$; and chronic dissection, $55.9 \% \pm 5.2 \%)(P=.404)$ (Figure E3, B). Freedom from stroke was $85.3 \% \pm 1.5 \%$ at 5 years and $78.9 \% \pm 2.3 \%$ at 10 years (Figure E3, $C$ ) and it was also similar in each aortic pathologies 


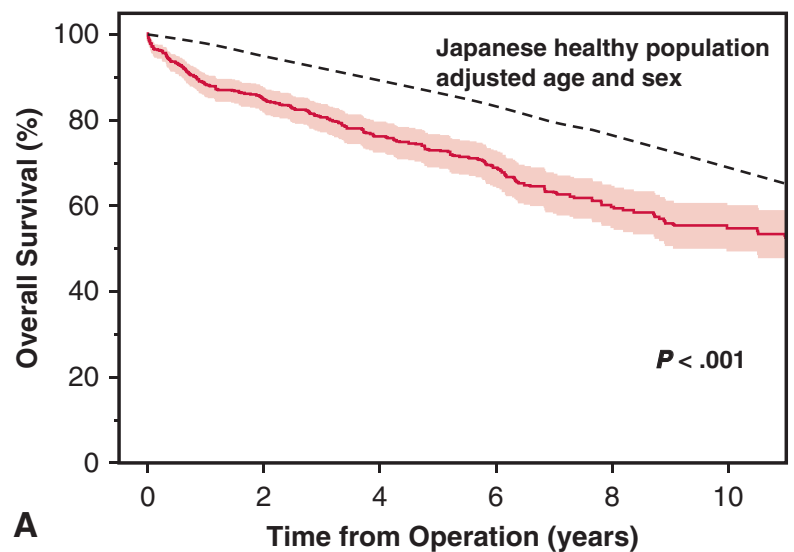

Number at risk

$\begin{array}{llllll}655 & 471 & 323 & 238 & 139 & 90\end{array}$

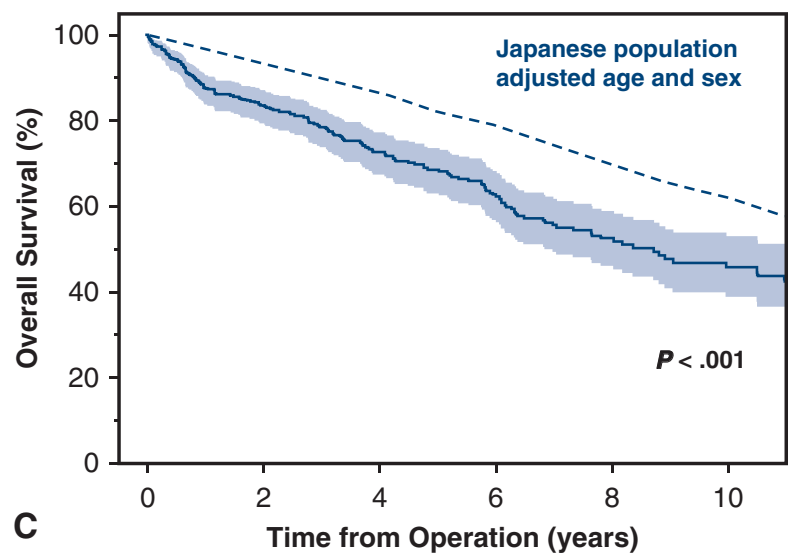

Number at risk

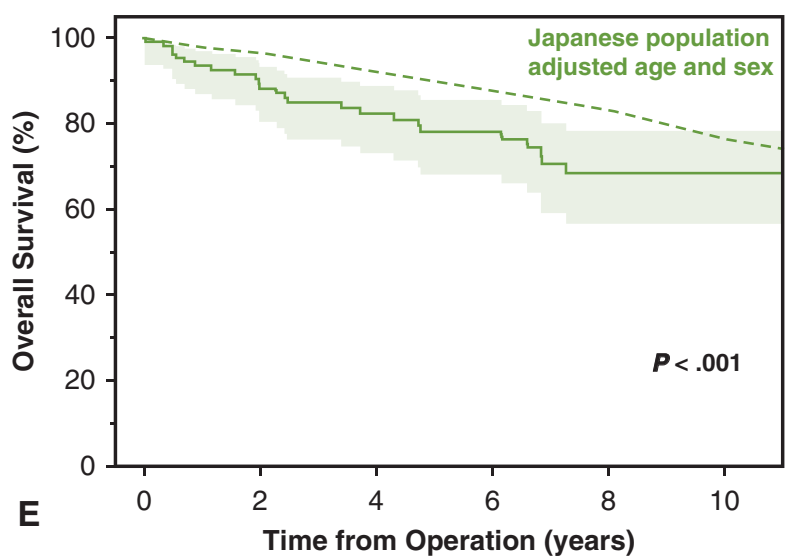

Number at risk

$$
\begin{array}{llllll}
107 & 82 & 63 & 49 & 29 & 21
\end{array}
$$

FIGURE 1. A, Overall survival. B, Overall survival by pathology: non-dissection (blue line), acute dissection (red line), and chronic dissection (green line). Significant differences were found between non-dissection and acute dissection as well as non-dissection and chronic dissection. Overall survival in the Japanese healthy population adjusted for age and sex. C, Non-dissection. D, Acute dissection. E, Chronic dissection. 
TABLE 5. Univariate and multivariate analysis of overall survival (Cox hazard analysis)

\begin{tabular}{|c|c|c|c|c|}
\hline \multirow[b]{2}{*}{ Variable } & \multicolumn{2}{|c|}{ Univariate } & \multicolumn{2}{|c|}{ Multivariate } \\
\hline & HR $(95 \%$ CI $)$ & $\overline{P \text { value }}$ & HR $(95 \%$ CI $)$ & $\overline{P \text { value }}$ \\
\hline Age (y) & $1.07(1.05-1.08)$ & $<.001 *$ & $1.06(1.04-1.08)$ & $<.001 *$ \\
\hline Female & $1.02(0.76-1.35)$ & .891 & & \\
\hline Hypertension & $0.79(0.59-1.08)$ & .133 & & \\
\hline Dyslipidemia & $0.95(0.70-1.28)$ & .752 & & \\
\hline Diabetes mellitus & $1.03(0.69-1.49)$ & .882 & & \\
\hline Smoking & $0.94(0.72-1.22)$ & .625 & & \\
\hline eGFR $\left(\mathrm{mL} / \mathrm{min} / 1.73 \mathrm{~m}^{2}\right)$ & $0.97(0.97-0.98)$ & $<.001 *$ & $0.98(0.97-0.99)$ & $<.001 *$ \\
\hline Chronic lung disease & $1.69(1.24-2.28)$ & $.001 *$ & $1.12(0.79-1.55)$ & .519 \\
\hline Coronary artery disease & $1.59(1.20-2.09)$ & $.001 *$ & $0.83(0.56-1.23)$ & .357 \\
\hline Marfan syndrome & $0.34(0.08-0.90)$ & $.026^{*}$ & $1.44(0.34-4.20)$ & .574 \\
\hline Old cerebral infarction & $1.69(1.15-2.41)$ & $.009 *$ & $1.31(0.88-1.90)$ & .184 \\
\hline Previous thoracic aortic surgery & $1.23(0.83-1.77)$ & 298 & & \\
\hline No dissection & $1.80(1.36-2.42)$ & $<.001 *$ & $1.12(0.79-1.59)$ & .527 \\
\hline Atherothrombotic aorta & $1.60(0.96-2.49)$ & .068 & & \\
\hline Malperfusion & $0.80(0.43-1.34)$ & .419 & & \\
\hline Shock status & $1.22(0.67-2.01)$ & .495 & & \\
\hline Cardiac arrest & $4.35(1.54-9.52)$ & $.009 *$ & $1.78(0.61-4.13)$ & .264 \\
\hline Infection & $1.35(0.58-2.67)$ & .452 & & \\
\hline Rupture & $2.54(1.55-3.94)$ & $<.001 *$ & $1.52(0.89-2.45)$ & .119 \\
\hline Nonelective operation & $0.90(0.67-1.20)$ & .493 & & \\
\hline CPB time (min) & $1.00(1.00-1.00)$ & .449 & & \\
\hline Myocardial ischemic time (min) & $1.00(0.99-1.00)$ & .058 & & \\
\hline Circulation arrest of lower body (min) & $1.00(0.99-1.00)$ & .423 & & \\
\hline Antegrade cerebral perfusion & $1.15(0.76-1.80)$ & .529 & & \\
\hline Cerebral perfusion time (min) & $1.00(1.00-1.00)$ & .760 & & \\
\hline Minimal tympanic temperature $\left({ }^{\circ} \mathrm{C}\right)$ & $1.03(0.97-1.09)$ & .317 & & \\
\hline Minimal rectal temperature $\left({ }^{\circ} \mathrm{C}\right)$ & $0.99(0.92-1.05)$ & 656 & & \\
\hline Concurrent procedures & $1.41(1.08-1.84)$ & $.011 *$ & $1.47(1.01-2.11)$ & $.043^{*}$ \\
\hline Permanent neurologic deficit & $2.04(1.26-3.13)$ & $.005^{*}$ & $3.31(1.79-5.79)$ & $<.001^{*}$ \\
\hline Transient neurologic deficit & $1.14(0.72-1.72)$ & .558 & & \\
\hline Mediastinitis & $2.19(0.86-4.51)$ & .092 & & \\
\hline Tracheostomy & $4.48(3.09-6.32)$ & $<.001 *$ & $2.38(1.53-3.60)$ & $<.001^{*}$ \\
\hline Hoarseness & $1.57(1.13-2.15)$ & $.008^{*}$ & $1.29(0.91-1.79)$ & .146 \\
\hline Renal failure & $4.64(3.02-6.84)$ & $<.001^{*}$ & $2.53(1.57-3.97)$ & $<.001 *$ \\
\hline
\end{tabular}

$H R$, Hazard ratio; $C I$, confidence interval; $e G F R$, estimated glomerular filtration rate; $C P B$, cardiopulmonary bypass. $* P<.05$.

$(P=.613)$. After discharge, 42 patients were diagnosed with a new stroke based on image assessment.

Apart from 11 patients with postoperative mediastinitis, graft infection occurred in 6 patients $(0.9 \%)$. Four of those 6 patients underwent surgical repair. One patient underwent ascending aorta replacement at 6.1 years. Two patients underwent descending aorta replacement due to elephant trunk infection at 1.5 and 6.4 years. In addition, 1 patient underwent descending aorta repair for aortoesophageal fistula due to previous stentgraft. One patient was complicated with aortoesophageal fistula in 0.5 years. The patient and family rejected open repair and debridement, and he died 2 months later. The last patient, who experienced graft infection of the Bentall graft in 3.8 years, died from sepsis under medical treatment at another institution.

The overall incidence of pseudoaneurysm was $2.2 \%$ (14 out of 625 patients). The incidence of pseudoaneurysm was similar between proximal and distal anastomosis $(1.0 \%$ and $1.2 \%$, respectively). There were no significant differences in the incidence of pseudoaneurysm across the aortic 
TABLE 6. The mode of reoperation

\begin{tabular}{lc}
\hline \multicolumn{1}{c}{ Procedure } & n (\%) \\
\hline Repeated operation & $18(2.7)$ \\
Root replacement for proximal pseudoaneurysm & $5(0.8)$ \\
Ascending Ao replacement for proximal & $2(0.3)$ \\
pseudoaneursym & \\
Ascending Ao replacement for graft infection & $1(0.2)$ \\
Descending Ao replacement for graft infection & $3(0.5)$ \\
TEVAR for distal pseudoaneursym & $4(0.6)$ \\
TEVAR for residual dissection in aortic arch & $1(0.2)$ \\
TEVAR for ET kinking & $1(0.2)$ \\
TEVAR for AEF & $1(0.2)$ \\
Additional operation & $85(13.0)$ \\
Root replacement & $3(0.5)$ \\
Descending Ao replacement & $10(1.5)$ \\
TAAA & $38(5.8)$ \\
Extent I & 5 \\
Extent II & 16 \\
Extent III & 14 \\
Extent IV & 3 \\
TEVAR & $34(5.2)$ \\
\hline
\end{tabular}

Ao, Aorta, TEVAR, thoracic endovascular aortic repair; ET, elephant trunk; $A E F$, aorto-esophateal fistula; TAAA, thoracoabdominal aortic aneurysm.

pathologies $(P=.864)$. No pseudoaneurysm and aneurysmal dilatation in the arch vessel anastomoses were diagnosed during the observation period, and there were no restenosis or occlusion of branch grafts.

\section{DISCUSSION}

Although strides have been made to improve early outcomes, the value of long-term outcomes following total arch replacement remains controversial. It has been reported that 5-year survival after total arch replacement was $69.3 \%$ to $86.7 \%$ in 3.3 to 4.5 years of follow-up, and freedom from reoperation was $86.0 \%$ to $97.8 \%$ at 5 years. ${ }^{12,18-22}$

In comparison to our previous report (5-year survival was $79.6 \% \pm 3.3 \%$ and 10 -year survival was $71.2 \% \pm 5.0 \%$ in $2.4 \pm 2.3$ years of follow-up, respectively), ${ }^{7}$ our present study shows lower survival rates $(73.1 \% \pm 1.9 \%$ at 5 years and $54.8 \% \pm 2.7 \%$ at 10 years). The difference in survival rates between our previous data and the current data can be attributed to our ability to analyze the number and the cause of late deaths more accurately (51 late deaths in our previous report and 190 late deaths in this report) in the longer follow-up period $(5.0 \pm 4.1$ years and $97.1 \%$ patients were followed for longer than 1 year). In investigating the causes of death, we demonstrated that $>80 \%$ of patients died of nonaortic disease in their late phase. However, it is possible that this number was underestimated because patients who died from pneumonia due to dysphagia caused by stroke or hoarseness or senility due to falling down caused by postoperative frail deterioration were not included in aorta-related death.
This study demonstrated that 3 perioperative factors (ie, older age, chronic kidney disease, and concurrent procedures) and 3 postoperative complications (ie, PND, tracheostomy, and renal failure) were significant risk factors for late death. Age and chronic kidney disease could not be altered preoperatively and have broad spectrum. It was difficult to set a definitive cut-off value of each factor. Indeed, we do not determine surgical indication from single variable. Although we previously reported that concomitant coronary artery bypass grafting was not a risk factor for hospital mortality, ${ }^{23}$ in the perspective of late survival, less-invasive treatment might be considered in patients who have multiple risk factors to decrease surgical invasion. Preoperative hemodynamic status was not a significant risk factor in multivariate analysis. In serious situations, total arch replacement was a reasonable option from a long-term perspective, given that the patient was in a low-risk group, because in the subgroup analysis of octogenarians/nonagenarians $(\mathrm{n}=127)$ emergent surgery was a significant risk factor for late death (HR, 2.05; 95\% CI, 1.03-3.80; $P=.042$ ). Moreover, we also demonstrated that some postoperative complications were significant risk factors for late death. Therefore, to improve late outcomes, cardiothoracic surgeons should aim to not only to prevent late aortic events but also to prevent postoperative complications.

Regarding reoperation, freedom from repeated aortic surgery was significantly lower in patients with acute dissection. The use of gelatin-resorcinol-formaldehyde glue was considered to be the cause of glue necrosis because it was used at our institution from 1999 to $2010 .^{24}$ The toxic effect caused recurrent dissection and pseudoaneurysm formation at the anastomosis site. Luehr and colleagues ${ }^{25}$ reported on 1232 patients who underwent elective total arch replacement in several centers, noting that 6 patients $(0.4 \%)$ required reoperation for pseudoaneurysm in a 4.1 year follow-up period. Our data indicate that $2.2 \%$ of patients developed pseudoaneursym. In addition, graft infection is a serious complication, although the incidence was low $(0.9 \%$; 6 out of 655 patients). However, no operative mortality was found in all 4 patients who underwent surgical repair and debridement. As in our previous report, ${ }^{26}$ aggressive surgical treatment is essential in this cohort. Even in the late phase, periodic follow-up is needed.

Moreover, freedom from additional operations was significantly lower in patients with chronic dissection. As recently reported, ${ }^{27,28}$ total arch replacement with elephant trunk contributes to positive aortic remodeling of the descending aorta in acute dissection. Frozen elephant trunk also had a significant remodeling effect in acute dissection, whereas the effect of positive remodeling is smaller in chronic dissection. ${ }^{29}$ Oda and colleagues ${ }^{30}$ reported that the risk of rupture increased with an aortic diameter $\geq 5.0 \mathrm{~cm}$ in patients with chronic dissection in the descending or thoracoabdominal aorta. Based on these 

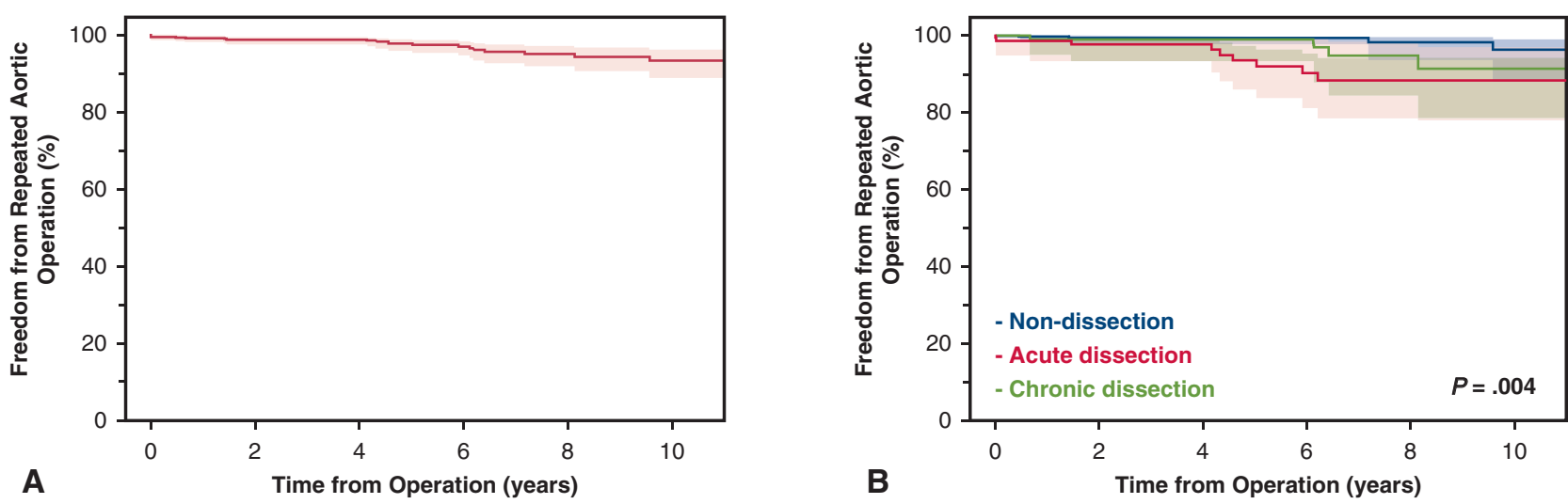

Number at risk $\begin{array}{lllll}655 & 461 & 317 & 230 & 133\end{array}$

$\begin{array}{lrccccc}\text { Number at risk } & & & & & \\ \text { Non-dissection: } & 399 & 281 & 182 & 132 & 72 & 46 \\ \text { Acute dissection: } & 149 & 101 & 74 & 51 & 34 & 19 \\ \text { Chronic dissection: } 107 & 80 & 63 & 49 & 29 & 20\end{array}$

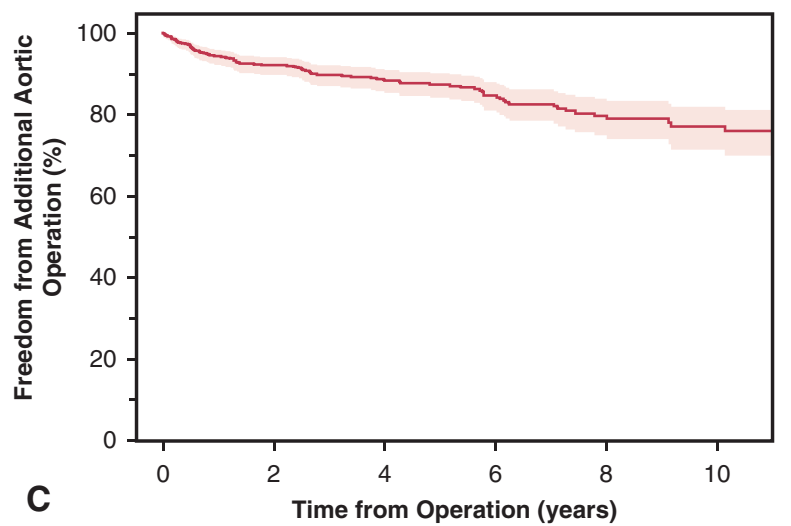

Number at risk

Time from Operation (years)

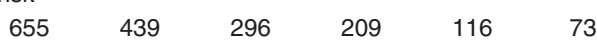

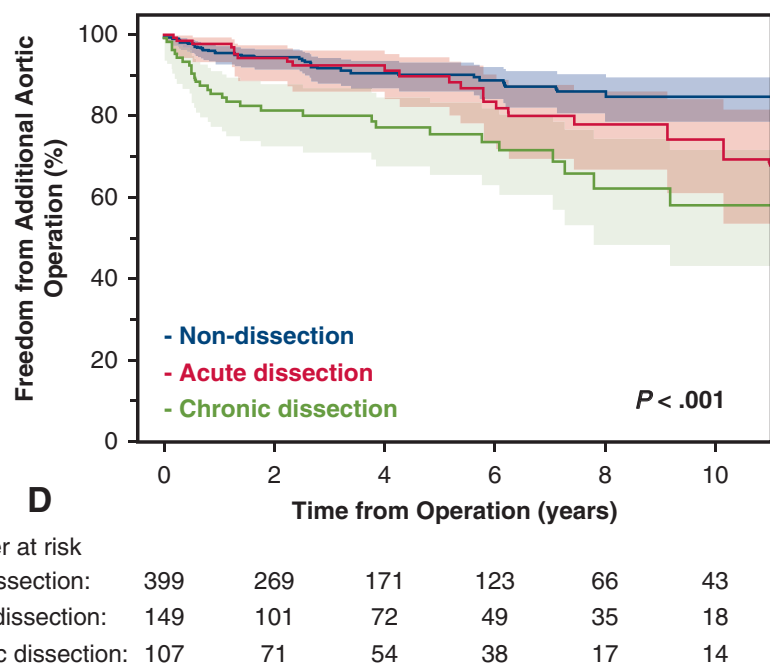

FIGURE 2. A, Freedom from repeated aortic operation. B, Freedom from repeated aortic operation by pathology: non-dissection (blue line), acute dissection (red line), and chronic dissection (green line). A significant difference was found between non-dissection and acute dissection. C, Freedom from additional aortic operation. D, Freedom from additional aortic operation by pathology: non-dissection (blue line), acute dissection (red line), and chronic dissection (green line). non-dissection (blue line), acute dissection (red line), and chronic dissection (green line). Significant differences were found between (non-dissection and chronic dissection as well as acute dissection and chronic dissection).

data, it is critical to consider late dilation of the downstream aorta before initial total arch replacement of the aortic arch aneurysm itself. However, the result that only 3 patients $(0.5 \%)$ required additional aortic root replacement following initial total arch replacement supports our surgical indication of aortic root.

Individual anastomosis of each arch vessel using 4-branched graft could provide a secure anastomosis. The greatest advantage of 4-branched graft over en bloc reconstruction is the ability to transect each vessel at an appropriate cross-section, avoiding atherosclerotic plaques. This strategy contributed to fewer adverse neurologic outcomes in patients with an atherothrombotic aorta from the perspective of both early and long-term outcomes. Moreover, in this observation period, 1 patient with connective tissue disease who underwent en bloc reconstruction of arch vessels developed cuff dilatation, whereas no pseudoaneurysms or dilation of arch vessels were found in the individual reconstruction group.

Some authors reported that 5-year survival after hybrid repair was $54.3 \%$ to $84 \%$ in 1.9 to 4.5 years of follow-up, and freedom from reoperation was $80.0 \%$ to $91.9 \%$ at 5 years. ${ }^{11,31-33}$ These midterm results suggest that hybrid repair has become an alternative option. However, the high incidence of stroke after hybrid treatment is still controversial $(2.8 \%-11.6 \%)^{21,34}$ and 
inferior reintervention-free rate is also a problem. ${ }^{12}$ Careful patient selection with a strategy to reduce embolization is required. We believe that our long-term results can be a helpful benchmark in decision making.

There are several limitations to our study. First, it was a retrospective study from a single center. Second, during the observation period our surgical technique evolved; for example, retrograde cerebral perfusion was used until $2002(\mathrm{n}=49)$ and ACP was used after 2002. We included all patients because earlier patients provided more longterm results. Third, the Cox hazard model included 9 continuous variables and 25 categorical variables. The unavailability of continuous variables limited the quality of model building. Fourth, the Cox hazard model also included a couple of variables related to postoperative complications (eg, mediastinitis, tracheostomy, renal failure, PND, and TND). These variables occurred after time 0 and might bring in bias into the model. Fifth, 106 patients $(16.2 \%)$ received follow-up at other hospitals and 19 patients $(2.9 \%)$ did not receive follow-up within 1 year. Sixth, there were 16 late deaths the cause of which is unknown. Last, events such as repeated surgery on the aorta, additional aortic surgery, and MAAEs may include medical decision bias. Moreover, for stroke we only included hospital events.

\section{CONCLUSIONS}

The long-term outcomes of total arch replacement using 4-branched graft were favorable. Meticulous preoperative risk assessment and endeavors to prevent postoperative complications may contribute to improvements in late outcomes. Acute dissection was a significant risk factor for repeat surgery on the aorta, whereas chronic dissection was a significant predictor of additional surgeries on the aorta. Even in the late phase, periodic follow-up was required to prepare for subsequent aorta-related events.

\section{Webcast}

You can watch a Webcast of this AATS meeting presentation by going to: https://aats.blob.core.windows.net/ media/18AO/26-br-1400-okita-v2.mp4.

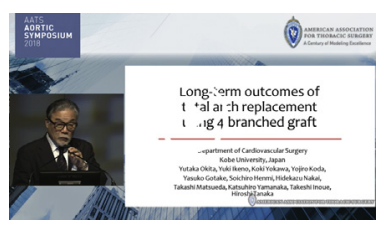

\section{Conflict of Interest Statement}

Authors have nothing to disclose with regard to commercial support.

\section{References}

1. Ueda Y, Miki S, Kusuhara K, Okita Y, Tahata T, Yamanaka K. Surgical treatment of aneurysm or dissection involving the ascending aorta and aortic arch, utilizing circulatory arrest and retrograde cerebral perfusion. J Cardiovasc Surg (Torino). 1990;31:553-8.

2. Svensson LG, Crawford ES, Hess KR, Cosselli JS, Raskin S, Shenaq SA, et al. Deep hypothermia with circulatory arrest. Determinants of stroke and early mortality in 656 patients. J Thorac Cardiovasc Surg. 1993;106:19-28.

3. Kazui T, Washiyama N, Muhammad BA, Terada H, Yamashita K, Takinami M. Improved results of atherosclerotic arch aneurysm operations with a refined technique. J Thorac Cardiovasc Surg. 2001;121:491-9.

4. Okada K, Omura A, Kano H, Sakamoto T, Tanaka A, Inoue T, et al. Recent advancements of total aortic arch replacement. J Thorac Cardiovasc Surg. 2012; 144:139-45.

5. Ogino H, Sasaki H, Minatoya K, Matsuda H, Tanaka H, Watanuki H, et al. Evolving arch surgery using integrated antegrade selective cerebral perfusion: impact of axillary artery perfusion. J Thorac Cardiovasc Surg. 2008; 136:641-8.

6. Minatoya K, Ogino H, Matsuda H, Sasaki H, Tanaka H, Kobayashi J, et al. Is conventional aortic arch surgery justifiable in octogenarians? J Thorac Cardiovasc Surg. 2010;139:641-5.

7. Okita Y, Okada K, Omura A, Kano H, Minami H, Inoue T, et al. Total arch replacement using antegrade cerebral perfusion. J Thorac Cardiovasc Surg. 2013;145:63-71.

8. Shrestha M, Kaufeld T, Beckmann E, Fleissner F, Umminger J, Abd Alhadi F, et al. Total aortic arch replacement with a novel 4-branched frozen elephant trunk prosthesis: single-center results of the first 100 patients. J Thorac Cardiovasc Surg. 2016;152:148-59.

9. Miyahara S, Miyata H, Motomura N, Takamoto S, Okita Y. Clinical significance of chronic obstructive pulmonary disease in patients undergoing elective total arch replacement: analysis based on the japan adult cardiovascular surgery database. Eur J Cardiothorac Surg. 2017;51:761-6.

10. Okita Y. Surgery for thoracic aortic disease in japan: evolving strategies toward the growing enemies. Gen Thorac Cardiovasc Surg. 2015;63:185-96.

11. Shijo T, Kuratani T, Torikai K, Shimamura K, Sakamoto T, Kubo T, et al. Thoracic endovascular aortic repair for degenerative distal arch aneurysm can be used as a standard procedure in high-risk patients. Eur J Cardiothorac Surg. 2016;50:257-63.

12. Yoshitake A, Okamoto K, Yamazaki M, Kimura N, Hirano A, Ida Y, et al. Comparison of aortic arch repair using the endovascular technique, total arch replacement and staged surgery. Eur J Cardiothorac Surg. 2017;51:1142-8.

13. Seike Y, Matsuda H, Fukuda T, Inoue Y, Omura A, Uehara K, et al. Total arch replacement versus debranching thoracic endovascular aortic repair for aortic arch aneurysm: what indicates a high-risk patient for arch repair in octogenarians? Gen Thorac Cardiovasc Surg. 2018;66:263-9.

14. Nozdrzykowski M, Luehr M, Garbade J, Schmidt A, Leontyev S, Misfeld M, et al. Outcomes of secondary procedures after primary thoracic endovascular aortic repair. Eur J Cardiothorac Surg. 2016;49:770-7.

15. Overman DM, Jacobs JP, Prager RL, Wright CD, Clarke DR, Pasquali SK, et al. Report from the Society of Thoracic Surgeons National Database Workforce: clarifying the definition of operative mortality. World J Pediatr Congen Heart Surg. 2013;4:10-2.

16. Japanese Ministry of Health, Labor and Welfare. Japanese population life table. Available at: http://www.mhlw.go.jp/toukei/saikin/hw/life/life15/index.html. Accessed July 27, 2016.

17. Finkelstein DM, Muzikansky A, Aschoenfeld DA. Comparing survival of a sample to that of a standard population. J Natl Cancer Inst. 2003;95:1434-9.

18. Ius F, Fleissner F, Pichlmaier M, Karck M, Martens A, Harverich A, et al. Total aortic arch replacement with the frozen elephant trunk technique: 10-year follow-up single-centre experience. Eur J Cardiothorac Surg. 2013;44: 949-57.

19. Preventza O, Garcia A, Cooley DA, Tuluca A, Simpson KH, Bakaeen FG, et al. Reprint of: reoperations on the total aortic arch in 119 patients: Short- and midterm outcomes, focusing on composite adverse outcomes and survival analysis. $J$ Thorac Cardiovasc Surg. 2015;149:59-64.

20. Inoue Y, Minatoya K, Oda T, Itonoga T, Seike Y, Tanaka H, et al. Surgical outcomes for acute type A aortic dissection with aggressive primary entry resection. Eur J Cardiothorac Surg. 2016;50:567-73.

21. Hiraoka A, Chikazawa G, Totsugawa T, Tamura K, Ishida A, Sakaguchi T, et al. Objective analysis of midterm outcomes of conventional and hybrid aortic arch repair by propensity-score matching. J Thorac Cardiovasc Surg. 2017;154:100-6. 
22. Larsen M, Trimarchi S, Patel HJ, Di Eusanio M, Greason KL, Peterson MD, et al. Extended versus limited arch replacement in acute type A aortic dissection. Eur J Cardiothorac Surg. 2017;52:1104-10.

23. Okada K, Omura A, Kano H, Ohara T, Shirasaka T, Yamanaka K, et al. Short and midterm outcomes of elective total aortic arch replacement combined with coronary artery bypass grafting. Ann Thorac Surg. 2012;94:530-6.

24. Tanaka H, Ikeno Y, Abe N, Takahashi H, Inoue T, Okita Y. Outcomes of valvesparing root replacement in acute type a aortic dissection. Eur J Cardiothorac Surg. 2018;53:1021-6.

25. Luehr M, Peterss S, Zierer A, Pacini D, Etz CD, Shrestha ML, et al. Aortic events and reoperations after elective arch surgery: incidence, surgical strategies and outcomes. Eur J Cardiothorac Surg. 2018;53:519-24.

26. Yamanaka K, Omura A, Nomura Y, Miyahara S, Shirasaka T, Sakamoto T, et al. Surgical strategy for aorta-related infection. Eur J Cardiothorac Surg. 2014;46: 974-80.

27. Omura A, Miyahara S, Yamanaka K, Sakamoto T, Matsumori M, Okada K, et al. Early and late outcomes of repaired acute Debakey type I aortic dissection after graft replacement. J Thorac Cardiovasc Surg. 2016;151:341-8.

28. Inoue Y, Matsuda H, Omura A, Seike Y, Uehara K, Sasaki H, et al. Long-term outcomes of total arch replacement with the non-frozen elephant trunk technique for Stanford type A acute aortic dissection. Interact Cardiovasc Thorac Surg. 2018;27:455-60.

29. Iafrancesco M, Goebel N, Mascaro J, Franke UFW, Pacini D, Di Bartolomeo R, et al. Aortic diameter remodeling after the frozen elephant trunk technique in aortic dissection: results from an international multicenter registry. Eur J Cardiothorac Surg. 2017:52:310-8.

30. Oda T, Minatoya K, Sasaki H, Tanaka H, Seike Y, Itonaga T, et al. Surgical indication for chronic aortic dissection in descending thoracic and thoracoabdominal aorta. Circ Cardiovasc Interv. 2017;10.

31. Iba Y, Minatoya K, Matsuda H, Sasaki H, Tanaka H, Oda T, et al. How should aortic arch aneurysms be treated in the endovascular aortic repair era? A risk-adjusted comparison between open and hybrid arch repair using propensity score-matching analysis. Eur J Cardiothorac Surg. 2014;46: 32-9.

32. De Rango P, Ferrer C, Coscarella C, Musumeci F, Verzini F, Pogany G, et al Contemporary comparison of aortic arch repair by endovascular and open surgical reconstructions. J Vasc Surg. 2015;61:339-46.

33. Preventza O, Garcia A, Cooley DA, Haywood-Watson RJ, Simpson K Bakaeen FG, et al. Total aortic arch replacement: a comparative study of zone 0 hybrid arch exclusion versus traditional open repair. J Thorac Cardiovasc Surg. 2015;150:1591-8.

34. Melissano G, Tshomba Y, Bertoglio L, Rinaldi E, Chiesa R. Analysis of stroke after TEVAR involving the aortic arch. Eur J Vasc Endovasc Surg. 2012;43: 269-75.

Key Words: aortic arch replacement, total arch replacement, aortic aneurysm, aortic dissection 


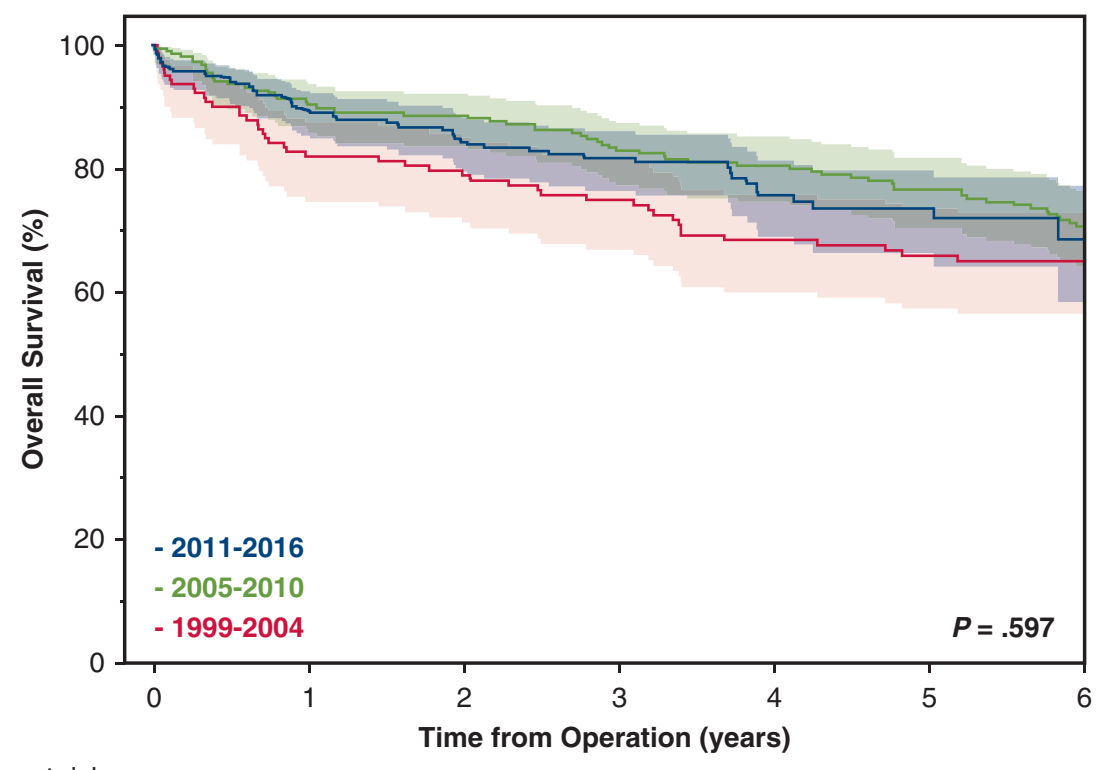

\begin{tabular}{|c|c|c|c|c|c|c|}
\hline \multicolumn{7}{|l|}{ Number at risk } \\
\hline 2011-2016: & 286 & 255 & 181 & 129 & 77 & 47 \\
\hline 2005-2010: & 226 & 196 & 191 & 174 & 165 & 156 \\
\hline 1999-2004: & 143 & 112 & 101 & 94 & 83 & 78 \\
\hline
\end{tabular}

FIGURE E1. Overall survival according to time from operation over 18 years. The first 6 years (1999-2004) (red line), the second 6 years (2005-2010) (green line), and the last 6 years (2011-2016) (blue line). 


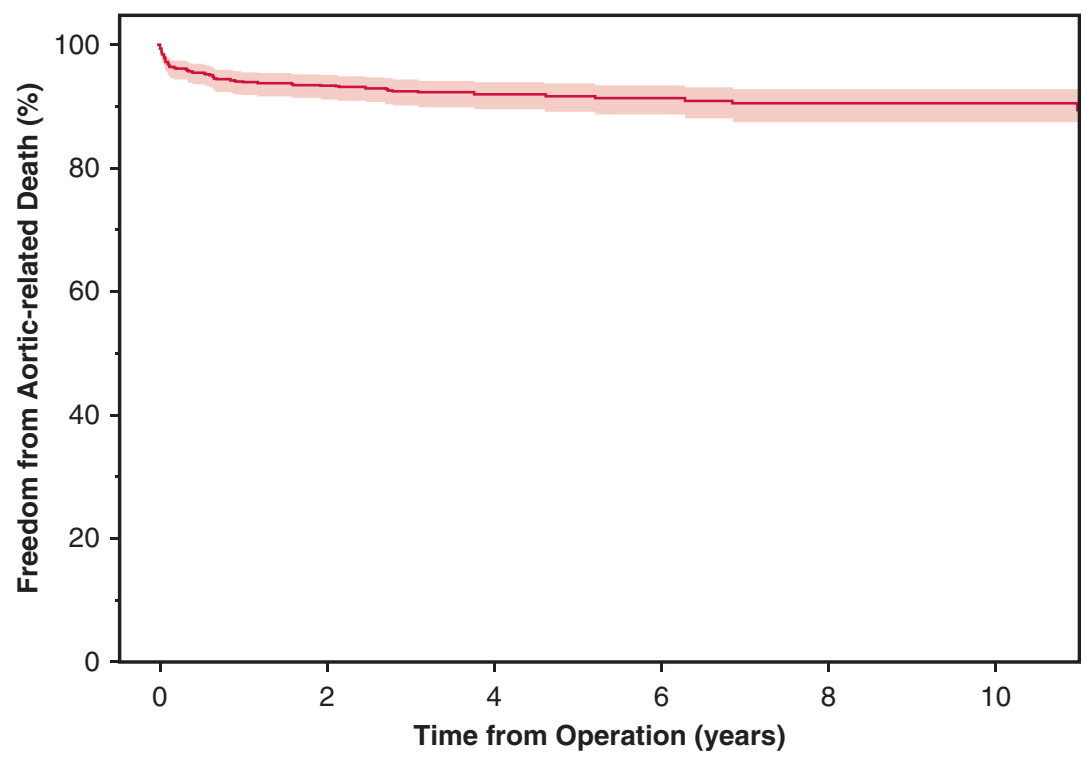

Number at risk

655

471

323

238

139

90

A

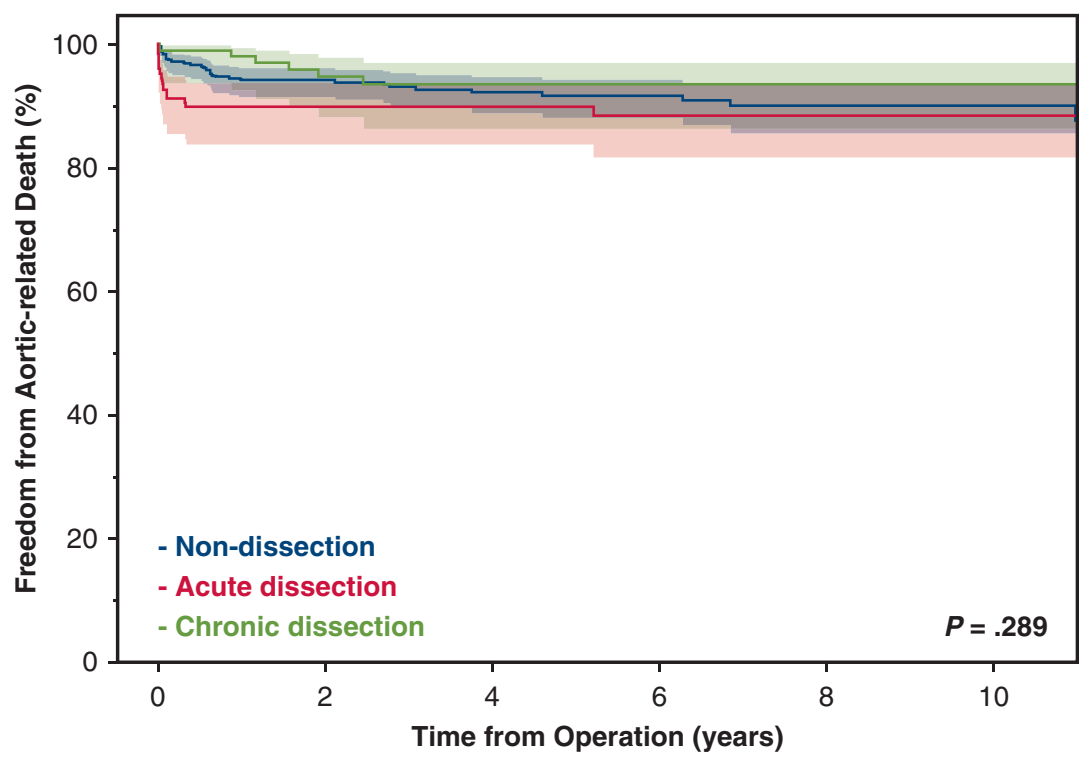

$\begin{array}{lcccccc}\text { Number at risk } & & & & & & \\ \text { Non-dissection: } & 399 & 283 & 185 & 136 & 73 & 48 \\ \text { Acute dissection: } & 149 & 107 & 77 & 55 & 39 & 23 \\ \text { Chronic dissection: } & 107 & 82 & 63 & 49 & 29 & 21\end{array}$

B

FIGURE E2. A, Freedom from aortic-related death. B, Freedom from aortic-related death by pathology: non-dissection (blue line), acute dissection (red line), and chronic dissection (green line). 


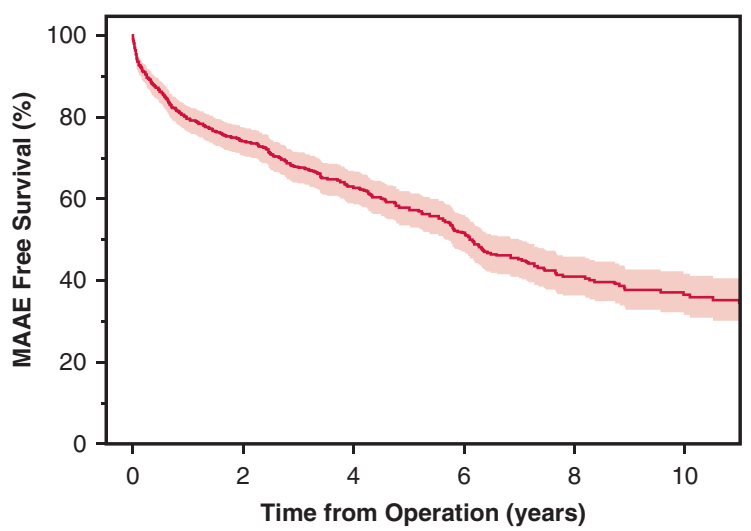

Number at risk

$\begin{array}{llllll}655 & 414 & 277 & 188 & 101 & 62\end{array}$

A

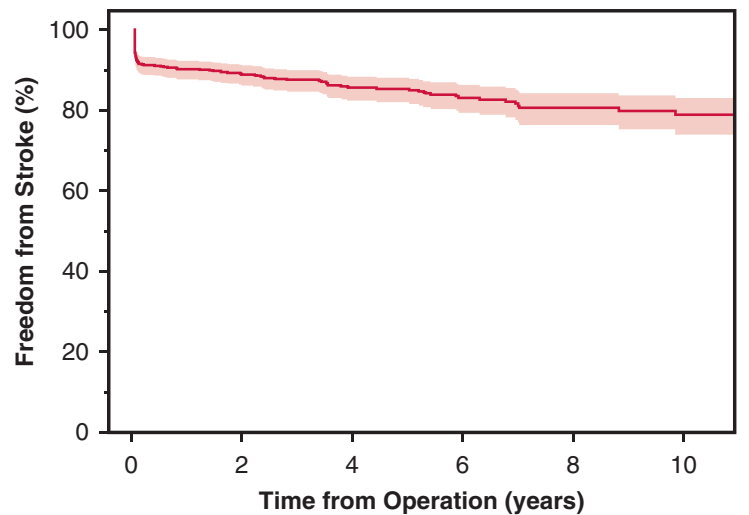

Number at risk

C

FIGURE E3. A, Survival without major adverse aortic event (MAAE). B, MAAE-free survival by pathology: non-dissection (blue line), acute dissection (red line), and chronic dissection (green line). $\mathrm{C}$, Freedom from stroke.

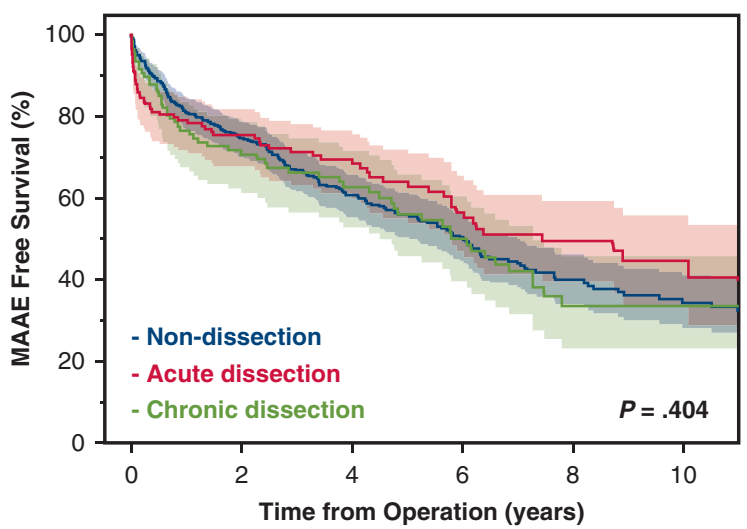

Number at risk

$\begin{array}{lllllll}\text { Non-dissection: } & 399 & 254 & 160 & 112 & 60 & 38\end{array}$

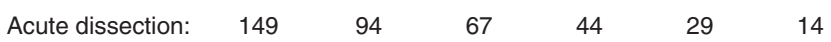
$\begin{array}{lllllll}\text { Chronic dissection: } & 107 & 68 & 52 & 34 & 14 & 12\end{array}$

B Time from Operation (years)

$\begin{array}{llllll}655 & 432 & 289 & 208 & 123 & 85\end{array}$

